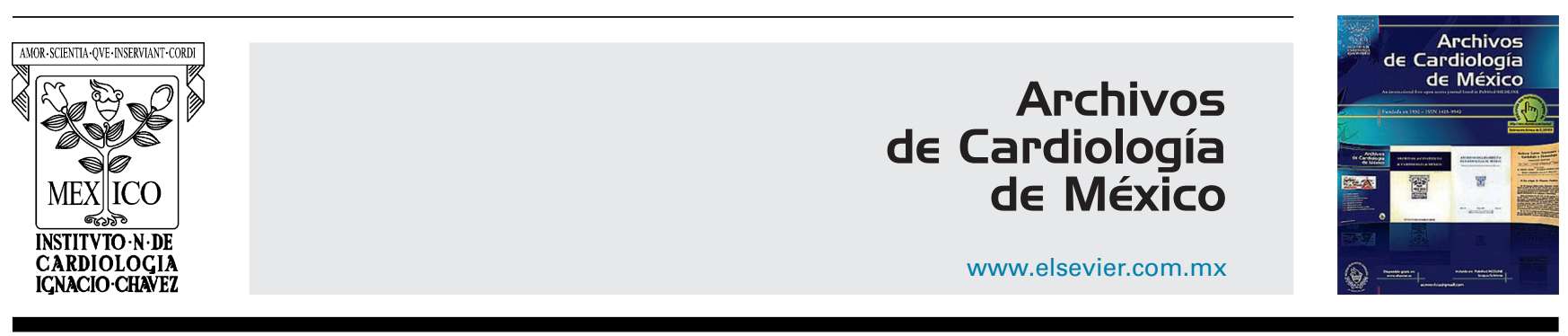

EDITORIAL

\title{
Un hombre del Renacimiento y un pensador de la llustración en el siglo xxı. En el nonagésimo cumpleaños de Alfredo de Micheli
}

\section{A Renaissance man and an Enlightenment thinker in 21st Century. In the ninetieth birthday of Alfredo de Micheli}

\author{
Raúl Izaguirre Ávila*
}

Departamento de Hematología, Instituto Nacional de Cardiología Ignacio Chávez, Ciudad de México, México

Recibido el 5 de septiembre de 2016; aceptado el 24 de noviembre de 2016

\begin{abstract}
Alfredo de Micheli ha tenido la dicha de celebrar su nonagésimo cumpleaños en total lucidez. Nacido el 9 de marzo de 1926 en Cassano al Ionio, en la región de Calabria, Italia, la décima década de la vida lo ha sorprendido en plena jornada laboral: frente a su escritorio, terminando de redactar los artículos que pronto someterá a revisión editorial. A manera de un breve homenaje, aquí intento celebrar una vida profesional de productividad académica y cultural sin parangón en la vida institucional de nuestro país.

Llegado a México en 1957, ya traía una sólida formación médica adquirida en Italia y Bélgica que le permitió incorporarse al Instituto Nacional de Cardiología, como residente primero, y como investigador después. Desde entonces, ha dado una inigualable producción científica en el terreno de la cardiología, en particular en la vecto y electrocardiografía, que no me corresponde a mí narrar. Aquí quiero destacar la otra faceta de su quehacer académico, como estudioso de la cultura y de la historia de la medicina, camino en el que siguió a su venerado maestro Ignacio Chávez. En este aspecto, tal vez es el discípulo que mejor asimiló el con-
\end{abstract}

* Calle Juan Badiano 1. Col. Sección XVI. Tlalpan. C.P. 14080. México, D.F.

Correo electrónico: rizagui@yahoo.com cepto integral del médico, como un ente en el que debe fusionarse la iatrotécnica y el humanismo.

En Alfredo de Micheli se han destacado las más altas cualidades humanas, en especial la inteligencia, el entendimiento, la razón, la búsqueda incesante del conocimiento, la transmisión del saber, la tolerancia, la humildad, el corazón noble y la generosidad. Su formación lo hace un hombre completo, en el más amplio sentido de la naturaleza humana, que utiliza al máximo las capacidades intelectuales y de sensibilidad que poseemos. Se erige como un hombre del Renacimiento, término derivado de la expresión italiana rinascita, y usado por primera vez por el literato Petrarca y revalorada por el arquitecto y teórico Giorgio Vasari, para referirse a un movimiento que hace resucitar en el arte y la cultura los valores espirituales de la antigüedad clásica.

Alfredo de Micheli es como el humanista del Renacimiento: un erudito, un hombre culto, enamorado de la antigüedad y preocupado por el estudio de todas las disciplinas en el campo del saber. Se siente atraído por la filosofía y se centra en el estudio de la cultura clásica, en el estudio del hombre como individuo y en su capacidad intelectual para explorar todos los campos del saber: ciencia, filosofía, arte. .

El individuo del Renacimiento tiene curiosidad por la naturaleza y por el hombre, al que considera un ser dotado 
de cualidades perfectas. Busca la felicidad gozando lo que la vida ofrece. El ideal es un hombre completo, armónicamente desarrollado en lo físico y en lo espiritual, que no limita su saber a un campo concreto, sino abierto a lo universal. La plena confianza que se tiene en el hombre da lugar al antropocentrismo. $Y$ eso ha caracterizado la actuación de Alfredo de Micheli. Como un prototipo de humanista, se interesa por el intelectualismo de este periodo, que hizo avanzar el mundo de las ciencias. Tal como la aparición de la imprenta ayudó a la difusión de los saberes en el Renacimiento, De Micheli se preocupa, en el siglo xxı, por difundir aquí y allá el conocimiento, la investigación, la cultura y la historia. Como hombre de espíritu renacentista, en el terreno cognoscitivo trata de profundizar en las aplicaciones y fundamentos de la ciencia; se interesa por el origen y la aparición de las universidades y por los personajes que han forjado el conocimiento médico actual: Galileo, Miguel Servet ${ }^{1}$, Realdo Colombo, Juan Valverde de Amuzco y muchos más ${ }^{2}$. Ha dedicado numerosas publicaciones al estudio y origen del método científico, que cristalizó en el Barroco en el pensamiento de Francis Bacon ${ }^{3}$ y en el descubrimiento de la circulación sanguínea ${ }^{4}$. Ha estudiado con minuciosidad la obra de William Harvey ${ }^{5,6}$, con la que se inicia el camino de la fisiología experimental ${ }^{7}$ a la fisiología actual ${ }^{8}$, así como el problema del calor animal y de la respiración? 9 .

Para De Micheli no hay límites en el conocimiento, ni en la curiosidad, ni en las lenguas. En este rubro es privilegiado. Su intelecto no conoce de limitaciones y se alimenta de fuentes escritas en numerosos idiomas. Su lengua materna, el dialecto calabrés; su lengua paterna, el dialecto lombardo; su lengua nacional, el italiano; las estudiadas en su formación inicial: griego y latín; las estudiadas en el liceo: el francés y el inglés. Además, aprendió algo de flamenco durante su formación en Bélgica. El portugués y el alemán no le son ajenos. El español ha sido un idioma natural para él, por el castellano que ha quedado en el dialecto del sur de Italia. Su dominio de las lenguas lo hace corregir la gramática, la sintaxis y la ortografía en italiano, francés y español.

Tampoco hay limitaciones para abordar el conocimiento en las diferentes esferas: le interesa el macrocosmos, como la astronomía, y estudia la obra de Galileo, pero también de Copérnico, de Tycho Brahe y de Kepler y cómo influyeron para cambiar la concepción del universo ${ }^{10}$. En el microcosmos, le atrae la anatomía ${ }^{11}$, la fisiología, la electricidad $^{12}$ y su descubrimiento en los animales ${ }^{13}$, la producción del calor por los seres vivos ${ }^{14}$, así como el origen del electrocardiograma ${ }^{15}$. En el mesocosmos se interesa en el método científico ${ }^{16,17}$ y en la clínica, pero también en las academias médicas ${ }^{18}$ y científicas $^{19,20}$, en el origen de las instituciones de enseñanza médica ${ }^{21}$ y la evolución de los hospitales ${ }^{22}$, así como en las vacunaciones ${ }^{23}$ y el tabaquismo ${ }^{24}$. Como buen humanista, sabe de los grandes movimientos sociales, de la emancipación de los pueblos y de las revoluciones, de las gestas épicas, de las exploraciones y de las grandes expediciones científicas que el hombre ha emprendido ${ }^{25,26}$, todos ellos fenómenos que observa con una visión integradora y de los que obtiene lecciones que puede aplicar en el entorno. Como hombre del Renacimiento, Alfredo de Micheli no tiene fronteras geográficas y encaja perfectamente en la moderna globalización del siglo XXI, el sueño renacentista de Carlos V: porque De Micheli no solo ha sido un calabrés o italiano o europeo o mexicano en México. Alfredo de Micheli es un hombre universal que brilla desde México, y el escenario de su quehacer intelectual ha sido el Instituto Nacional de Cardiología Ignacio Chávez.

Sus primeros estudios escolares transcurrieron en su natal Calabria y los de secundaria en el Colegio Alla Querce de Florencia, Italia. Cursó la carrera de medicina en las universidades de Nápoles y Módena y posteriormente hizo la residencia de Medicina Interna y de Hematología en Pavía, donde recibió enseñanzas de los alumnos de Adolfo Ferrata, el creador de la teoría del hemohistioblasto y el hemocitoblasto, entre los que destacan Stortti, Baserga, Introzzi y De Nicola. Cursó la especialidad de cardiología en el Hospital Universitario Saint Pierre de Bruselas, en el servicio del profesor Jean Lequime. Publicó su primer trabajo científico en 1954, antes de su llegada a México, sobre la enfermedad tuberculosa del bazo. Apareció en la revista que fundara Ferrata: Haematologica ${ }^{27}$.

A la numerosa lista de publicaciones que ha hecho sobre cardiología hay que sumar los trabajos dedicados no solo a la historia de la medicina, sino también a la historia universal, a la historia de la Nueva España y del México Independiente, y aún más, varios trabajos sobre literatura. Su prolífica pluma cultural empezó a dar frutos desde la década de 1950, con publicaciones que aparecieron en Italia y Bélgica, como Visiones de Bruselas y de Brabante ${ }^{28}$, Visioni del Belgio, Los intelectuales italianos y el Risorgimiento, publicada para la conmemoración del centenario de la independencia italiana en 1961, así como, Tras las fuentes de Dante, Los libros italianos en la Nueva España del siglo XVII ${ }^{29}$, Libros médicos en las bibliotecas de la Nueva España, Corrientes de cultura entre Italia y la Nueva España, Los primeros libros médicos novohispanos, Autores italianos en la Biblioteca de la Nacional y Pontificia Universidad de México ${ }^{30}$. También ha hecho publicaciones en periódicos nacionales, como las aparecidas en Excelsior: Presencia y estancia de italianos en la Nueva España y en el México independiente, Participación de médicos y cirujanos criollos y extranjeros en la lucha por la independencia, Las idas y venidas, azares e infortunios de Lorenzo Boturini, pionero del guadalupanismo; Participación de médicos y cirujanos en la lucha del Congreso Constituyente y la Reforma del siglo XIX, A los cien años de la muerte de Garibaldi, En el octavo centenario del nacimiento del santo del amor, Médicos y cirujanos en defensa de la patria (1843-1847).

Las revistas que se han visto enriquecidas por sus aportaciones a la cultura general van desde la Revista de la Universidad de México, pasando por las revistas ItaliaMéxico, Prensa Médica Mexicana, Acta Científica Potosina, Revista de la Universidad de San Luis Potosí, Revista del Colegio de México, Logos, la revista de filosofía de la Universidad La Salle, Ciencia, la Revista de la Académica Mexicana de Ciencias, Principia Cardiologica, revistas sudamericanas y en especial Archivos de Cardiología de México, la Gaceta Médica de México y la Revista de Investigación Clínica.

Si se consulta un buscador de internet, como Google, el nombre de Alfredo de Micheli despliega miles de resultados. Varios de sus artículos han sido incluidos en fichas bibliográficas y bases de datos electrónicas, que van desde universidades norteamericanas y sudamericanas, hasta universidades europeas. He encontrado sus artículos como 
fichas bibliográficas en bases de datos de Polonia, Inglaterra, Sri Lanka y los Estados Unidos, solo por citar algunos.

De los artículos que se pueden consultar por internet registrados en bases de datos, el que tuve el privilegio de publicar con él, En torno a la historia de las transfusiones sanguíneas $^{31}$, registra hasta el momento de escribir este trabajo 7,786 visitas y descargas ${ }^{32}$, seguido por Tabaco y tabaquismo en la historia de México y Europa ${ }^{33}$ con 5,982 visitas $^{32}$ y En torno a la respiración del llamado calor Animal con 2,533 citas $^{34}$. El artículo En torno a la evolución de los hospitales ${ }^{35}$ lo he encontrado como sustento de numerosas páginas de internet en inglés que tratan de la historia de los hospitales ${ }^{36}$, así como en libros alemanes ${ }^{37}$. Las páginas de varios hospitales de Norteamérica y Europa citan ese artículo cuando narran el desarrollo de sus instituciones hospitalarias y en la base de datos Imbiomed tiene 5,785 visitas y descargas ${ }^{38}$. Por ejemplo, la página www.enacademic.com, un diccionario enciclopédico electrónico, en el artículo sobre la palabra hospital, registra la referencia de De Micheli como única fuente en español entre 30 referencias en inglés ${ }^{39}$.

Esto revela que con la aparición del internet Alfredo de Micheli se convirtió en uno de los autores más consultados y referidos. Invariablemente, su nombre va asociado al del Instituto Nacional de Cardiología, con lo que no solo ha dado fama a la institución en el terreno cardiológico, sino en el ámbito de la cultura universal. Nuevamente, esto corresponde al De Micheli renacentista y globalizado del siglo xxI. Temas de su especial interés han sido el desarrollo del método científico ${ }^{40}$, el pensamiento ilustrado, la Ilustración en la Nueva España ${ }^{41}$, donde ha hecho contribuciones sobre sus admirados personajes novohispanos como Benito Díaz de Gamarra ${ }^{42}$, Antonio Alzate y Francisco Javier Clavijero ${ }^{43}$, solo por citar algunos.

Experto en la cultura y filosofía de la antigüedad grecorromana, describe las situaciones diarias de la vida con frases del latín clásico. Amante de la poesía, en su mente tiene grabados versos de Dante y Petrarca, que declama en italiano a la primera oportunidad. En el ámbito literario ha publicado artículos como el Petrarquismo en la Nueva España y Acerca de las influencias petrarquistas en España y la naciente poesía novohispana, este último en la Revista de Literatura Mexicana $^{44,45}$. En el terreno de la historia mexicana, trabajos como Médicos y medicina en la Nueva España del siglo XVI han sido utilizados como apoyo en capítulos sobre lingüística y sobre el significado de las palabras por autores de la universidad de Texas $^{46}$ y de la universidad de Roma. He encontrado su nombre en trabajos y discursos de personajes de la política y de la ciencia, así como en trabajos especializados concentrados en el Consejo Superior de Investigaciones Científicas de España ${ }^{47}$ e incluso en un trabajo sobre «Las garantías penales en la constitución de 1857 en perspectiva juscomparatista», escrito por el jurista argentino Eugenio Raúl Zaffaroni ${ }^{48}$ al recibir el grado de Dr. Honoris Causa por la Universidad Michoacana de San Nicolás de Hidalgo, donde hace referencia al trabajo sobre los médicos que participaron en el Congreso y en la Guerra de Reforma, que De Micheli publicó en la Gaceta Médica de México en $2001^{49}$.

Es difícil cuantificar su producción escrita en el terreno de la cultura. He logrado reunir más de 60 artículos y capítulos de temas culturales y de historia de la ciencia y de la medicina. En algunas revistas nacionales, llegaron a aparecer hasta 5 artículos de su autoría en el mismo número: 4 de investigación y uno de cultura. $Y$ han aparecido hasta 4 capítulos de historia de la medicina en un mismo volumen, como es el caso del libro Contribuciones italianas a la medicina mexicana, de Jesus Kumate ${ }^{50}$.

Su devoción por el Instituto Nacional de Cardiología, y en particular por Ignacio Chávez, queda de manifiesto en el constante recurrir a los pensamientos del maestro, a las citas que frecuentemente hace de sus conceptos, a la difusión de sus escritos y de algunas frases que resumen el humanismo y la creatividad del padre de la institución. Todo ello demuestra que Alfredo de Micheli no solo es un hombre renacentista, sino un pensador ilustrado, en el sentido que Emmanuel Kant dio en su definición de la llustración: la emancipación de la conciencia humana del estado de ignorancia y error, por medio del conocimiento. Una posición crítica, nacida del campo del pensamiento y de las ideas que intentó repensar en un nuevo idioma, los valores y creencias de la civilización occidental. El hombre de la Ilustración aspira a lograr la felicidad por medio de la libertad que le da el conocimiento útil de las cosas, proporcionado por la razón. Esos anhelos de la llustración, esa idea de luz, de iluminación del intelecto, liberan al hombre de las ataduras a lo material. De Micheli ha encontrado, como los humanistas del Renacimiento y los pensadores de la Ilustración, la felicidad en el saber, en las ideas, en la intelectualidad, esos niveles superiores donde todas las cosas se resuelven con sencillez, con lógica, con tranquilidad y armonía. Un mundo rico, al que pocos, en nuestra turbulenta época, pueden ingresar. Un estado superior que deja atrás las vanalidades materiales, de las que sencillamente Alfredo de Micheli ha prescindido, porque de nada le servirían. Su mundo: las ideas, el saber y la razón; su actuar: el humanismo; su misión: encontrar y difundir el conocimiento; su pasión: el Instituto Nacional de Cardiología Ignacio Chávez.

Han pasado 60 años desde que Alfredo de Micheli llegó a México. En su nonagésimo cumpleaños, detengámonos a contemplar y celebrar su fecunda labor académica haciendo este merecido elogio a su grandeza dentro de la medicina y de la cultura nacional. En palabras de la filósofa chilena Giuseppina Grammatico, hagamos homenaje al tenaz luchador y al perseverante maestro que ha fusionado una gran inteligencia y una firme voluntad con límpidas cualidades morales, que le han ganado un entrañable cariño entre sus alumnos y colegas. Al hombre de virtudes y al amigo de afectos y lealtades inmutables, siempre atento de lo que ocurre a su alrededor y siempre influyendo en su entorno; al amigo y al maestro con quien se comparten tribulaciones, cavilaciones y satisfacciones y de quien se tiene siempre apoyo y consejo. Es un orgullo de las instituciones que se han distinguido con su presencia. En su nonagésimo cumpleaños, deseamos que Alfredo de Micheli permanezca entre nosotros por muchos años.

\section{Financiación}

No se recibió patrocinio de ningún tipo para llevar a cabo este artículo. 


\section{Conflicto de intereses}

El autor declara no tener ningún conflicto de intereses.

\section{Agradecimiento}

\section{Al biólogo Mario Fuentes, jefe de la Biblioteca del Instituto Nacional de Cardiología Ignacio Chávez por las facilidades para localizar material bibliográfico antiguo.}

\section{Bibliografía}

1. De Micheli A. Miguel Servet y la circulación sanguínea pulmonar. Arch Cardiol Mex. 2003;73:171-4.

2. De Micheli A. En torno a los orígenes de la ciencia moderna. Gac Med Mex. 2003;139:513-7.

3. De Micheli A. Por una síntesis de la evolución conceptual hacia la medicina científica. Gac Med Mex. 1999;135:67-72.

4. De Micheli A. Bosquejo histórico del descubrimiento de la circulación sanguínea. Principia Cardiologica. 1988;4:23-30.

5. De Micheli A. William Harvey y los inicios de la ciencia médica moderna. Gac Méd Méx. 2005:141.

6. De Micheli A. En torno a la integración de la doctrina circulatoria y su difusión en América. Rev Inst Med Sucre. 2004; LXIX 124:90-9.

7. De Micheli A. En torno a los fundamentos del método científico. Principia Cardiologica. 1985;1:37-9.

8. De Micheli A. Los orígenes de la medicina experimental. Rev Fac Med. 1986;29:99-102.

9. De Micheli A. En torno a la respiración y al llamado calor animal. Rev Invest Clin. 2001;53:462-7.

10. De Micheli A, Izaguirre R. La ciencia europea de la Nueva España. Ciencia. 2010;61:22-9.

11. De Micheli A, Izaguirre R. Acerca de los estudios morfológicos en humanos en la Nueva España y en el México decimonónico. Rev de Invest Clín. 2007;59:318-23.

12. De Micheli A, Iturralde P, Izaguirre R. How electricity was discovered and how it is related to cardiology. Arch Cardiol Mex. 2012;82:252-9.

13. De Micheli A. Luigi Galvani y la electricidad animal. Rev Fac Med. 1991;34:36-43.

14. De Micheli A. Bosquejo histórico de los estudios sobre la respiración animal. Rev Fac Med. 1991;34:58-64.

15. De Micheli A. En torno al centenario de la electrocardiografía. Arch Inst Cardiol Mex. 1988;58:265-71.

16. De Micheli A. Consideraciones en torno al empleo de métodos racionales en el quehacer cardiológico. Arch Cardiol Mex. 2006;76 Supl 4:7-9.

17. De Micheli A. Algunos enfoques epistemológicos en medicina. Gac Méd Méx. 2004;140:557-61.

18. De Micheli A. En torno al cxx aniversario de la Academia Nacional de Medicina. Rev Fac Med. 1984;27:251-4.

19. De Micheli A. De academias y académicos. Bosquejo histórico. Gac Med Mex. 2003;139:281-5

20. De Micheli A. Recordando la creación de la primera Academia Científica. Rev Inst Med Sucre. 2006;LXX1:102-3.

21. De Micheli A. El sesquicentenario de la Facultad de Medicina de la Universidad Nacional. II. La antigua Facultad. Arch Cardiol Mex. 1983;53:271.
22. De Micheli A. De los hospitales u hospicios a los modernos institutos nacionales de salud. Arch Cardiol Mex. 2016;86:75-8.

23. De Micheli A. Doscientos años de la vacunación antivariolosa. Gac Med Mex. 2002;138:83-7.

24. De Micheli A. El tabaco a la luz de la historia y la medicina. Arch Cardiol Mex. 2015;85:318-22.

25. De Micheli A, Izaguirre R. De la herbolaria medicinal novohispana a los inicios de estudios botánico-farmacológicos sistematizados. Arch Cardiol Mex. 2009;79 Supl:95-101.

26. De Micheli A, Izaguirre A. La vacunación antivariólica antes y después de Jenner. Rev Invest Clin. 2011;63:84-9.

27. Pederzini A, de Micheli A. Un caso di tubercolosi splenica isolata. Haematologica. 1954;38:927-38.

28. De Micheli A. Visiones de Bruselas y de Brabante. Revista de la Universidad de México; 1958. p. 21-2.

29. De Micheli A. Los libros italianos en la Nueva España del siglo xVII. Revista de la Universidad de México; 1976. p. 39-42.

30. De Micheli A. Autores italianos en la Biblioteca de la Nacional y Pontificia Universidad de México. Acta Científica Potosina. 1981;8:67-102.

31. Izaguirre R, de Micheli A. En torno a la historia de las transfusiones sanguíneas. Rev Invest Clin. 2002;54:552-8.

32. http://www.imbiomed.com.mx/1/1/autores.php?method= listArticlebyAuthor\&id_revista=2\&id_autor $=10992$

33. De Micheli A, Izaguirre R. Tabaco y tabaquismo en la historia de México y de Europa. Revista de Investigación clínica. 2005;57:608-13.

34. http://www.imbiomed.com.mx/1/1/autores.php?method= listArticlebyAuthor\&id_revista=2\&id_autor $=2026$

35. De Micheli A. En torno a la evolución de los hospitales. Gac Med Mex. 2005;141:57-62.

36. http://everything.explained.today/History_of_hospitals

37. Stolberg G, Vanja C. Historia hospitalium. Berlin: Lit Verlag; 2013. p. 7.

38. http://www.imbiomed.com.mx/1/1/autores.php?method= listArticlebyAuthor\&id_revista=2\&id_autor $=2026$

39. http://en.academic.ru/dic.nsf/enwiki/11004409

40. De Micheli A. Filosofía ciencia, 36. Logos (Revista de filosofía de la Universidad La Salle); 1986. p. 43-57.

41. De Micheli A. La medicina y la llustración en la Nueva España. Gac Med Mex. 1998;134:343-9.

42. De Micheli A. En torno a los orígenes, la evolución y las irradiaciones de la cardiología mexicana. Arch Cardiol Méx. 2014;84:314-9.

43. De Micheli A. Un mexicano en la Italia del siglo de las luces. La Palabra y el Hombre, 81. Editorial Universidad Veracruzana; 1992. p. 85-93.

44. https://revistas-filologicas.unam.mx/literatura-mexicana/ index.php/lm/article/viewFile/556/554

45. https://es.wikipedia.org/wiki/Petrarquismo

46. http://cvc.cervantes.es/lengua/esletra/pdf/03/009_marcos. pdf

47. http://digital.csic.es/bitstream/10261/44167/1/JPardoTomas2011-Anatom\%C3\%ADas\%20del\%20Nuevo\%20Mundo.pdf

48. http://www.circulodoxa.org/documentos/Zaffaroni\%20-\% 20Las\%20garantías.pdf

49. De Micheli A. Médicos y cirujanos en el Congreso Constituyente (1856-1857) y en la Guerra de Reforma (1858-1860). Gac Med Mex. 2001;137:79-83.

50. Kumate J. Italia en la Medicina. México: El Colegio Nacional; 1997. 